\title{
PRODUCTS OF DIGRAPHS AND THEIR COMPETITION GRAPHS
}

\author{
MARTin SonntaG \\ Faculty of Mathematics and Computer Science \\ TU Bergakademie Freiberg \\ Prüferstraße 1, D-09596 Freiberg, Germany \\ e-mail: sonntag@tu-freiberg.de \\ AND \\ Hanns-Martin TeicherT \\ Institute of Mathematics \\ University of Lübeck \\ Ratzeburger Allee 160, D-23562 Lübeck, Germany \\ e-mail: teichert@math.uni-luebeck.de
}

\begin{abstract}
If $D=(V, A)$ is a digraph, its competition graph (with loops) $C G^{l}(D)$ has the vertex set $V$ and $\{u, v\} \subseteq V$ is an edge of $C G^{l}(D)$ if and only if there is a vertex $w \in V$ such that $(u, w),(v, w) \in A$. In $C G^{l}(D)$, loops $\{v\}$ are allowed only if $v$ is the only predecessor of a certain vertex $w \in V$. For several products $D_{1} \circ D_{2}$ of digraphs $D_{1}$ and $D_{2}$, we investigate the relations between the competition graphs of the factors $D_{1}, D_{2}$ and the competition graph of their product $D_{1} \circ D_{2}$.
\end{abstract}

Keywords: competition graph, product of digraphs.

2010 Mathematics Subject Classification: 05C76, 05C20.

\section{REFERENCES}

[1] J. Bang-Jensen and G. Gutin, Digraphs: Theory, Algorithms and Applications (Springer, London, 2001).

[2] J.E. Cohen, Interval graphs and food webs: a finding and a problem (Rand Corporation Document 17696-PR, Santa Monica, CA, 1968).

[3] W. Imrich and S. Klavžar, Product Graphs (John Wiley \& Sons, Inc., New York, 2000). 
[4] S.R. Kim, The competition number and its variants, in: Quo vadis, graph theory?, J. Gimbel, J.W. Kennedy and L.V. Quintas (Eds.), Ann. Discrete Math. 55 (1993) 313-326. doi:10.1016/s0167-5060(08)70396-0

[5] J.R. Lundgren, Food webs, competition graphs, competition-common enemy graphs and niche graphs, in: Applications of combinatorics and graph theory to the biological and social sciences, F. Roberts (Ed.), (IMA 17, Springer, New York, 1989) 221-243. doi:10.1007/978-1-4684-6381-1_9

[6] F.S. Roberts, Competition graphs and phylogeny graphs, in: Graph theory and combinatorial biology, L. Lovász (Ed.), (Proc. Int. Colloqu. Balatonlelle (Hungary) 1996, Bolyai Soc. Math. Studies 7, Budapest, 1999) 333-362.

[7] M. Sonntag and H.-M. Teichert, Competition hypergraphs, Discrete Appl. Math. 143 (2004) 324-329. doi:10.1016/j.dam.2004.02.010

[8] M. Sonntag and H.-M. Teichert, Competition hypergraphs of products of digraphs, Graphs Combin. 25 (2009) 611-624. doi:10.1007/s00373-005-0868-9

Received 20 November 2014

Revised 7 April 2015

Accepted 7 April 2015 